\title{
Lipid Profile Components and Subclinical Cerebrovascular Disease in the Northern Manhattan Study
}

\author{
Joshua Z. Willey ${ }^{a}$ Hannah Gardener ${ }^{d}$ Yeseon P. Moon ${ }^{a}$ Mitsuhiro Yoshita ${ }^{f}$ \\ Charles DeCarli Ying Kuen Cheung ${ }^{b}$ Ralph L. Sacco ${ }^{d}$ Mitchell S.V. Elkind ${ }^{a, c}$ \\ Clinton B. Wright ${ }^{d}$ \\ Departments of ${ }^{a}$ Neurology, ${ }^{b}$ Biostatistics, and ${ }^{c}$ Epidemiology, Columbia University, New York, N.Y., \\ ${ }^{d}$ Evelyn F. McKnight Brain Institute and the Department of Neurology, Miller School of Medicine, University of \\ Miami, Miami, Fla., and e Department of Neurology, University of California at Davis, Davis, Calif., USA; ${ }^{\mathrm{f}}$ Department \\ of Neurology, Hokuriku National Hospital, Nanto, Japan
}

\section{Key Words}

Plasma lipids · Risk Factors · White Matter · Silent Infarct

\begin{abstract}
Background: Subclinical cerebrovascular disease has been associated with multiple adverse events related to aging, including stroke and dementia. The modifiable risk factors for subclinical cerebrovascular disease beyond hypertension have not been well characterized. Our objective was to examine the association between baseline, and changes over time, in lipid profile components and subclinical cerebrovascular disease on magnetic resonance imaging (MRI). Methods: Fasting plasma lipids were collected on participants in the Northern Manhattan Study, a prospective cohort study examining risk factors for cardiovascular disease in a multiethnic elderly urban-dwelling population. A subsample of the cohort underwent brain MRI between 2003 and 2008 (a median of 6.2 years, range $=0-14$, after enrollment), when repeat fasting lipids were obtained. We used lipid profile components at the time of initial enrollment $(n=1,256$ with lipids available) as categorical variables, as well as change in clinical categories over the two measures $(n=1,029)$. The
\end{abstract}

main outcome measures were (1) total white matter hyperintensity volume (WMHV) using linear regression and (2) silent brain infarcts (SBI) using logistic regression. Results: None of the plasma lipid profile components at the time of enrollment were associated with WMHV. The association between baseline lipids and WMHV was, however, modified by apolipoprotein $E$ (apoE) status ( $X^{2}$ with 2 degrees of freedom, $p=0.03$ ), such that among apoE4 carriers those with total cholesterol (TC) $\geq 200 \mathrm{mg} / \mathrm{dl}$ had a trend towards smaller WMHV than those with TC $<200 \mathrm{mg} / \mathrm{dl}$ (difference in log WMHV $-0.19, p=0.07$ ), while there was no difference among apoE3 carriers. When examining the association between WMHV and change in lipid profile components we noted an association with change in high-density lipoprotein cholesterol (HDL-C, $>50 \mathrm{mg} / \mathrm{dl}$ for women, $>40 \mathrm{mg} / \mathrm{dl}$ for men) and TC. A transition from low-risk HDL-C ( $>50 \mathrm{mg} / \mathrm{dl}$ for women, $>40 \mathrm{mg} / \mathrm{dl}$ for men) at baseline to high-risk HDL-C at the time of MRI (vs. starting and remaining low risk) was associated with greater WMHV (difference in logWMHV 0.34, $p$ value 0.03 ). We noted a similar association with transitioning to a $\mathrm{TC} \geq 200 \mathrm{mg} / \mathrm{dl}$ at the time of MRI (difference in logWMHV 0.25 , $p$ value 0.006 ). There were no associations with baseline or change in lipid profile components with SBI. Conclu-

\section{KARGER}

E-Mail karger@karger.com

www.karger.com/ced
(C) 2014 S. Karger AG, Basel

1015-9770/14/0376-0423\$39.50/0
Joshua Z. Willey, MD

Neurological Institute

710 West 168th Street

New York, NY 10032 (USA)

E-Mail jzw2@ columbia.edu 
sions: The association of plasma lipid profile components with greater WMHV may depend on apoE genotype and worsening $\mathrm{HDL}$ and TC risk levels over time.

(C) 2014 S. Karger AG, Basel

\section{Introduction}

As the population ages, chronic diseases of aging will have a greater public health impact. Subclinical cerebrovascular disease, observed on magnetic resonance imaging (MRI) as white matter hyperintensities (WMH) and silent brain infarcts (SBI), increases the risk of important diseases of aging such as cognitive impairment, reduced mobility, and ischemic stroke $[1,2]$. The increased recognition of SBI and WMH highlights the importance of identifying modifiable risk factors so as to then allow for trials aimed at preventing diseases of aging associated with cerebrovascular injury. Plasma lipids are a major determinant of coronary artery disease, though the association with stroke remains less well established [3]. Total cholesterol (TC) and low-density lipoprotein cholesterol (LDL-C) levels tend to decline with age, though the plasma lipid profile components remain associated with cardiovascular disease across all age-groups [4]. Lowering LDL-C with statins is recommended as a coronary risk reduction strategy, and treatment with statins also reduces the risk of first and recurrent stroke $[5,6]$. The data on the role of dyslipidemia as a risk factor for ischemic stroke is more mixed with most studies showing neutral results or an association with only large-artery atherosclerotic subtypes [7].

Several gaps exist in our understanding of the determinants of SBI and WMH. Recognized cerebrovascular risk factors associate with $\mathrm{WMH}$, suggesting a vascular etiology, though nonischemic etiologies have also been proposed [8]. The latter may be supported by studies showing no association between WMH and established stroke risk factors such as physical activity [9]. Few studies, however, have examined the association of lipid profile components with subclinical measures of cerebrovascular brain injury such as WMH and SBI, with one prior study showing an inverse association between WMH volumes (WMHV) and dyslipidemia [10]. However, current literature is limited on the role of changes in plasma lipid profile components over time and the association with subclinical cerebrovascular disease, and few studies have included multiethnic populations with a high proportion of Hispanics. Furthermore there has been little work on whether the association of lipid profile components with
SBI and WMH could be modified by genetic risk factors, particularly apolipoprotein $\mathrm{E}$ (apoE) isoforms that are implicated in both lipid metabolism and neurodegenerative diseases [11].

The purpose of this analysis was to examine the association of lipid profile components of SBI and WMH in a cohort of Northern Manhattan residents and whether these effects would be modified by apoE status. We hypothesized that baseline higher levels, as well increases over time, in TC, triglycerides (TG), and LDL-C would be associated with a greater prevalence of SBI and larger WMHV, with an inverse association with high-density lipoprotein cholesterol (HDL-C).

\section{Methods}

\section{Recruitment of the Cohort}

The Northern Manhattan Study (NOMAS, $\mathrm{n}=3,298$ ) is a population-based prospective cohort study designed to evaluate the effects of medical, socioeconomic, and other risk factors on the incidence of vascular disease. Details regarding initial recruitment are available in prior publications [9]. Between 2003 and 2008 participants in NOMAS were invited to participate in an MRI substudy if they were older than 55 years of age, had not had a clinical stroke, and did not have a contraindication to MRI. In order to increase recruitment an additional 199 participants who were household members, but not blood relations, were invited to participate in the MRI substudy for a total of 1,290 participants. Compared to the overall cohort, the MRI substudy sample was younger and had a lower proportion of diabetes, hypertension, and cardiac disease [12]. The study was approved by the Institutional Review Boards at Columbia University Medical Center and the University of Miami. All participants gave informed consent to participate in the study. The authors report no conflicts of interest.

\section{Cohort Evaluation and Follow-Up}

Data regarding risk factors were collected through interviews of participants by trained bilingual research assistants at enrollment in the NOMAS cohort, as previously described [13]. In-person measurements and collection of fasting blood specimens were carried out by study physicians. Race-ethnicity was determined by self-identification. Standardized questions were adapted from the Behavioral Risk Factor Surveillance System by the Centers for Disease Control and Prevention regarding the following conditions: hypertension, diabetes mellitus, hypercholesterolemia, peripheral vascular disease, cigarette smoking, and cardiac conditions. Hypertension was defined as systolic blood pressure $\geq 140 \mathrm{~mm} \mathrm{Hg}$ or diastolic blood pressure $\geq 90 \mathrm{~mm} \mathrm{Hg}$ based on the average of two measurements $5 \mathrm{~min}$ apart in a seated position with a manual sphygmomanometer, or a patient's self-report of a history of hypertension or antihypertensive use. Diabetes mellitus was defined as fasting blood glucose $\geq 126 \mathrm{mg} / \mathrm{dl}$ or the patient's self-report of such a history, or insulin or hypoglycemic use. These same inperson measurements were repeated at the time of enrollment into the MRI substudy. 
We included only individuals for whom fasting lipids were available. A total of 1,256 participants enrolled in the MRI cohort had fasting blood samples with TC available from their time of initial enrollment into NOMAS. Of these, we have repeat lipid profiles collected at both baseline and the time of MRI with collection dates over 1 year apart among 1,029 participants. Lipids were measured as previously described [14]. Briefly, TC and TG levels were determined using standard enzymatic procedures in an automated spectrometer (Hitachi 705; Boehringer, Mannheim, Germany). Plasma HDL-C levels were measured after precipitation of apolipoprotein B-containing lipoproteins by phosphotungstic acid. LDL-C was calculated using the Friedewald formula [15]; the LDL$\mathrm{C}$ was listed as missing when the TG was greater than $400 \mathrm{mg} / \mathrm{dl}$ ( $\mathrm{n}=15$ at baseline, $\mathrm{n}=13$ on follow-up) [16].

ApoE alleles were determined by HhaI digestion of PCR products amplified from genomic DNA as described by Hixson and Vernier [17] using fasting blood samples at the time of the MRI. We considered apoE3/3 as the reference group, while carriers of one or two alleles of apoE4 were collapsed into the same category (i.e. apoE4/2, apoE4/3, apoE4/4); carriers of one or two alleles of apoE2 carriers were also collapsed into the same group (i.e. apoE2/2, apoE2/3) [11].

\section{MRI Data Acquisition}

Imaging was performed on a 1.5-tesla MRI system (Philips Medical Systems) at the Hatch Research Center at Columbia University. The processing of MRI scans in NOMAS has been previously described [12]. The presence or absence of brain infarction was determined from the size, location, and imaging characteristics of the lesion [18]. SBI was defined as a cavitation on the FLAIR sequence of at least $3 \mathrm{~mm}$ in size, and distinct from a vessel due to the lack of signal void on T2 sequence, and of equal intensity to cerebrospinal fluid without associated focal neurological complaints. Analyses for WMHV were performed using semiautomated measurements of pixel distributions and mathematical modeling of pixel-intensity histograms for cerebrospinal fluid and brain (white and gray matter) to identify the optimal pixel-intensity threshold to distinguish cerebrospinal fluid from brain matter. Analyses were performed using a custom-designed image analysis package (QUANTA 6.2 using a Sun Microsystems Ultra 5 workstation). WMHV was calculated as a proportion of total cranial volume to correct for differences in head size [19] and log-transformed to achieve a normal distribution (logWMHV) for analysis. All analyses were performed blind to participant identifying information.

\section{Statistical Analysis}

The primary predictors of interest were: (1) TC, HDL-C, LDL$\mathrm{C}$, and TG at the time of initial enrollment as binary variables using National Cholesterol Education Program-defined cutoffs for highrisk categories (TC $>200 \mathrm{mg} / \mathrm{dl}$, LDL-C $>130 \mathrm{mg} / \mathrm{dl}$, HDL-C $<40$ $\mathrm{mg} / \mathrm{dl}$ for men and $<50 \mathrm{mg} / \mathrm{dl}$ for women, and TG $>200 \mathrm{mg} / \mathrm{dl}$ ) [20] and their low-risk counterparts as the reference, and (2) change from the initial enrollment into NOMAS to the time of MRI in clinical categories defined as (a) low risk to high risk, (b) remaining high risk, (c) high risk to low risk and (d) remaining low risk as the reference. The primary outcomes of this analysis were total WMHV and SBI. We fitted linear regression models to examine the associations with total WMHV and logistic regression models with the outcome of SBI, unadjusted and adjusting for all lipid profile com-
Table 1. Characteristics of the NOMAS MRI cohort $(n=1,282)$ with baseline lipids

\begin{tabular}{lc}
\hline Age, years & $64.0 \pm 8.4$ \\
Men & $506(39)$ \\
Race-ethnicity & \\
Hispanic & $842(66)$ \\
Non-Hispanic Black & $220(17)$ \\
Non-Hispanic White & $191(15)$ \\
Education, completed high school & $588(46)$ \\
Risk factors & \\
Hypertension & $873(68)$ \\
Diabetes mellitus & $248(19)$ \\
Coronary artery disease & $209(16)$ \\
Current smoking & $201(16)$ \\
Waist circumference & $36.74 \pm 4.56$ \\
Physically inactive & $701(56)$ \\
Moderate alcohol intake & $527(41)$ \\
TC, mg/dl (proportion $>200 \mathrm{mg} / \mathrm{dl})$ & $201.3 \pm 38.9(51)$ \\
HDL-C, mg/dl (proportion $<40 \mathrm{mg} / \mathrm{dl}$ for & \\
$\quad$ men, $<50$ mg/dl for women) & $47.0 \pm 14.6(54)$ \\
LDL-C, mg/dl (proportion $>130 \mathrm{mg} / \mathrm{dl})$ & $128.1 \pm 35.2(47)$ \\
TG, mg/dl (proportion $>200 \mathrm{mg} / \mathrm{dl})$ & $134.6 \pm 81.8(14)$ \\
Treated with a statin before enrollment & \\
into the MRI cohort & $194(15.0)$ \\
ApoE genotype & \\
ApoE4/4, 4/3, 4/2 & $299(25)$ \\
ApoE3/3 & $782(65)$ \\
ApoE2/2, 2/3 & $130(11)$ \\
&
\end{tabular}

Values represent mean $\pm \mathrm{SD}$ or number (percent given in parentheses).

ponents, demographics (age, sex, race-ethnicity, and time interval between enrollment and MRI), and additional confounders (hypertension, diabetes mellitus, smoking, coronary artery disease, moderate alcohol consumption, physical activity, education, medical insurance status, body mass index, estimated glomerular filtration rate, apoE, and any use of cholesterol-lowering medications). Age, sex, race-ethnicity, treatment with any cholesterol-lowering medications (at enrollment and during follow-up), and apoE isoforms were considered in all models as possible effect modifiers. The improvement of model fit for models with multiple levels of categories was tested using a likelihood ratio test with appropriate degrees of freedom; stratified models were fitted when the $\mathrm{p}$ value for the likelihood ratio test was $<0.05$. All statistical analyses were performed using SAS version 9.2 (SAS Institute, Cary, N.C., USA).

\section{Results}

Baseline characteristics of the cohort available for this analysis $(\mathrm{n}=1,282)$ are shown in table 1 . Briefly, the mean age of the cohort was $64 \pm 8.4$ years; $61 \%$ were women. The majority were Hispanic, with a similar proportion of non-Hispanic Blacks and Whites making up the rest of 
Table 2. Plasma lipid panel components in the NOMAS MRI cohort from initial enrollment to the time of imaging $(\mathrm{n}=1,026)$

\begin{tabular}{lllll}
\hline & $\begin{array}{l}\text { High risk at baseline } \\
\text { and at the time of } \\
\text { MRI }\end{array}$ & $\begin{array}{l}\text { High risk at baseline } \\
\text { and low risk at the } \\
\text { time of MRI }\end{array}$ & $\begin{array}{l}\text { Low risk at baseline } \\
\text { and high risk at the } \\
\text { time of MRI }\end{array}$ & $\begin{array}{l}\text { Low risk at baseline } \\
\text { and at the time of } \\
\text { MRI }\end{array}$ \\
\hline HDL-C & $330(32.2)$ & $245(23.9)$ & $35(3.4)$ & $415(40.5)$ \\
LDL-C & $255(25.1)$ & $235(23.1)$ & $73(7.2)$ & $452(44.6)$ \\
TC & $323(31.5)$ & $206(20.0)$ & $119(11.6)$ & $378(36.8)$ \\
TG & $69(6.7)$ & $78(7.6)$ & $60(5.9)$ & $819(79.8)$ \\
\hline
\end{tabular}

Number of subjects with percent given in parentheses. High-risk categories: high TC (>200 mg/dl), high LDL-C (>130 mg/dl), high TG ( $>200 \mathrm{mg} / \mathrm{dl})$, low HDL-C ( $<40 \mathrm{mg} / \mathrm{dl}$ for men, $<50 \mathrm{mg} / \mathrm{dl}$ for women).

Table 3. Parameter estimates for the association between plasma lipid profile components at baseline and total WMHV in the NOMAS MRI cohort (linear regression)

\begin{tabular}{lllrl}
\hline Lipid profile component & $\begin{array}{l}\text { Unadjusted } \\
\text { parameter estimate } \\
\text { (p value) }\end{array}$ & $\begin{array}{l}\text { Model 1: adjusted } \\
\text { parameter estimate } \\
\text { (p value) }\end{array}$ & $\begin{array}{l}\text { Model 2: adjusted } \\
\text { parameter estimate } \\
\text { (p value) }\end{array}$ & $\begin{array}{l}\text { Model 3: adjusted } \\
\text { parameter estimate } \\
\text { (p value) }\end{array}$ \\
\hline Baseline HDL-C $(\mathrm{men}<40 \mathrm{mg} / \mathrm{dl}$, & & & & \\
$\quad$ & $-0.11(0.05)$ & $-0.073(0.2)$ & $-0.084(0.1)$ & $-0.067(0.3)$ \\
women $<50 \mathrm{mg} / \mathrm{dl})$ & $0.006(0.9)$ & $0.005(0.9)$ & $0.009(0.9)$ & $0.016(0.8)$ \\
Baseline LDL-C $>130 \mathrm{mg} / \mathrm{dl}$ & $-0.066(0.4)$ & $-0.031(0.7)$ & $-0.08(0.3)$ & $-0.093(0.3)$ \\
Baseline TG $>200 \mathrm{mg} / \mathrm{dl}$ & $0.025(0.6)$ & $0.017(0.7)$ & $0.027(0.6)$ & $0.041(0.5)$ \\
Baseline TC $>200 \mathrm{mg} / \mathrm{dl}$ & & & \\
\hline
\end{tabular}

Model 1: controlling for age at MRI, time from baseline to MRI, sex, race/ethnicity. Model 2: controlling for variables in model 1 and high school education, insurance, smoking, hypertension, diabetes, body mass index, moderate alcohol use, any physical activity, estimated glomerular filtration rate, apoE, and cholesterol-lowering medication use at baseline. Model 3: controlling for variables in model 2 and cholesterol-lowering medication use ever during follow-up before MRI.

the cohort. ApoE genotyping was available in $95 \%$ of the MRI cohort. Plasma lipid profile components were obtained a mean of 6.1 years before enrollment into the MRI cohort (median $=6.2$ years, range $=0-14$ years) and repeated at the time of the MRI. Means ( \pm standard deviations) of annual changes in the plasma lipid profile values were TC $(-1.2 \pm 6.3 \mathrm{mg} / \mathrm{dl})$, HDL-C $(1.2 \pm 1.8 \mathrm{mg} / \mathrm{dl})$, LDL-C $(-2.2 \pm 5.7 \mathrm{mg} / \mathrm{dl})$, and TG $(-1.3 \pm 13.0 \mathrm{mg} / \mathrm{dl})$. Table 2 outlines the distribution of categorical lipid profile change over time.

\section{Association between Baseline Plasma Lipid Profile Components and WMHV}

The association between lipid profile components and WMHV is presented in table 3 . In summary, none of the plasma lipid profile components at the time of enrollment was associated with WMHV. We found, however, that the effect of TC differed by apoE4 isoform (likelihood ratio test with 2 d.f., $\mathrm{p}=0.03)$. In stratified models high-risk TC $(>200 \mathrm{mg} / \mathrm{dl})$ versus low-risk TC $(<200 \mathrm{mg} / \mathrm{dl})$ re- vealed a trend toward an association with smaller WMHV among those who were apoE4-positive (difference in logWMHV $-0.19, \mathrm{p}=0.07$ ), whereas there was no association in those with other apoE isoforms (data not shown). We found no interactions with baseline demographics or treatment with cholesterol-lowering medications.

\section{Association between Categorical Change over Time in} Plasma Lipid Profile Components and WMHV

We examined the association between categorical change in lipids between enrollment and MRI (table 4). In fully adjusted models we found that a transition from a low-risk HDL-C category $(>50 \mathrm{mg} / \mathrm{dl}$ in women, $>40$ $\mathrm{mg} / \mathrm{dl}$ in men) at baseline to a high-risk category at follow-up was associated with greater WMHV (difference in $\log$ WMHV 0.34 , $\mathrm{p}$ value 0.03 ), using those who remained at low risk as the reference group. Compared to those with low-risk TG levels $(<200 \mathrm{mg} / \mathrm{dl})$ at both time points, those with a transition from a high-risk TG category (>200 mg/dl) to a low-risk category had a lower WMHV 
Table 4. Parameter estimates for change in plasma lipid profile components and total WMHV in the NOMAS MRI cohort (linear regression)

\begin{tabular}{|c|c|c|c|c|}
\hline $\begin{array}{l}\text { Lipid profile component changes }{ }^{1} \text { : } \\
\text { baseline category to MRI category }\end{array}$ & $\begin{array}{l}\text { Unadjusted } \\
\text { parameter estimate } \\
\text { (p value) }\end{array}$ & $\begin{array}{l}\text { Model } 1 \text { : adjusted } \\
\text { parameter estimate } \\
\text { ( } \mathrm{p} \text { value) }\end{array}$ & $\begin{array}{l}\text { Model 2: adjusted } \\
\text { parameter estimate } \\
\text { (p value) }\end{array}$ & $\begin{array}{l}\text { Model 3: adjusted } \\
\text { parameter estimate } \\
\text { ( } \mathrm{p} \text { value) }\end{array}$ \\
\hline \multicolumn{5}{|c|}{ TC (reference: low risk $\rightarrow$ low risk) } \\
\hline Low risk $\rightarrow$ high risk & $0.21(0.03)$ & $0.24(0.006)$ & $0.25(0.006)$ & $0.25(0.006)$ \\
\hline High risk $\rightarrow$ high risk & $0.10(0.2)$ & $0.11(0.09)$ & $0.12(0.07)$ & $0.14(0.04)$ \\
\hline High risk $\rightarrow$ low risk & $0.14(0.08)$ & $0.07(0.3)$ & $0.04(0.6)$ & $0.07(0.4)$ \\
\hline High risk $\rightarrow$ low risk & $-0.04(0.6)$ & $0.002(1.0)$ & $-0.04(0.6)$ & $-0.04(0.6)$ \\
\hline High risk $\rightarrow$ high risk & $-0.15(0.03)$ & $-0.04(0.5)$ & $-0.07(0.3)$ & $-0.07(0.3)$ \\
\hline \multicolumn{5}{|c|}{ LDL-C (reference: low risk $\rightarrow$ low risk) } \\
\hline Low risk $\rightarrow$ high risk & $0.03(0.8)$ & $0.10(0.3)$ & $0.05(0.7)$ & $0.11(0.6)$ \\
\hline High risk $\rightarrow$ low risk & $0.08(0.3)$ & $0.03(0.6)$ & $0.01(0.9)$ & $0.08(0.6)$ \\
\hline High risk $\rightarrow$ high risk & $-0.09(0.2)$ & $-1 \times 10^{-4}(1.0)$ & $0.006(0.9)$ & $0.07(0.7)$ \\
\hline
\end{tabular}

Model 1: controlling for age at MRI, time from baseline to MRI, sex, race/ethnicity. Model 2: controlling for variables in model 1 and high school education, insurance, smoking, hypertension, diabetes, body mass index, moderate alcohol use, any physical activity, estimated glomerular filtration rate, apoE, and cholesterol-lowering medication use at baseline. Model 3: controlling for variables in model 2 and cholesterol-lowering medication use ever during follow-up before MRI.

${ }^{1}$ High-risk categories: high TC (>200 mg/dl), high LDL-C (>130 mg/dl), high TG ( $\left.>200 \mathrm{mg} / \mathrm{dl}\right)$, low HDL-C (<40 mg/dl for men, $<50 \mathrm{mg} / \mathrm{dl}$ for women).

Table 5. Odds ratios (OR) and $95 \%$ confidence intervals (CI) for association of plasma lipid profile components and SBI $(\mathrm{n}=114)$ in the NOMAS MRI cohort

\begin{tabular}{|c|c|c|c|c|}
\hline Lipid profile component & $\begin{array}{l}\text { Unadjusted } \\
\text { OR and } 95 \% \text { CI }\end{array}$ & $\begin{array}{l}\text { Model 1: adjusted } \\
\text { OR and } 95 \% \mathrm{CI}\end{array}$ & $\begin{array}{l}\text { Model 2: adjusted } \\
\text { OR and } 95 \% \text { CI }\end{array}$ & $\begin{array}{l}\text { Model 3: adjusted } \\
\text { OR and } 95 \% \text { CI }\end{array}$ \\
\hline $\begin{array}{l}\text { Baseline HDL-C }(\text { men }<40 \mathrm{mg} / \mathrm{dl} \text {, } \\
\text { women }<50 \mathrm{mg} / \mathrm{dl})\end{array}$ & $0.94(0.63-1.40)$ & $1.04(0.68-1.59)$ & $0.95(0.60-1.52)$ & $0.84(0.52-1.37)$ \\
\hline Baseline LDL-C >130 mg/dl & $0.96(0.65-1.42)$ & $1.03(0.69-1.55)$ & $1.05(0.66-1.65)$ & $0.99(0.60-1.62)$ \\
\hline Baseline TG > $200 \mathrm{mg} / \mathrm{dl}$ & $0.95(0.51-1.77)$ & $1.03(0.54-1.94)$ & $0.95(0.47-1.91)$ & $0.84(0.40-1.77)$ \\
\hline Baseline TC > $200 \mathrm{mg} / \mathrm{dl}$ & $0.81(0.55-1.20)$ & $0.87(0.58-1.32)$ & $0.86(0.55-1.35)$ & $0.82(0.50-1.35)$ \\
\hline
\end{tabular}

Model 1: controlling for age at MRI, time from baseline to MRI, sex, race/ethnicity. Model 2: controlling for variables in model 1 and high school education, insurance, smoking, hypertension, diabetes, body mass index, moderate alcohol use, any physical activity, estimated glomerular filtration rate, apoE, and cholesterol-lowering medication use at baseline. Model 3: controlling for variables in model 2 and cholesterol-lowering medication use ever during follow-up before MRI.

(difference in logWMHV -0.23 , p value 0.03 ). For TC a transition from low risk of TC to high risk (difference in $\log \mathrm{WMHV} 0.25$, $\mathrm{p}$ value 0.006 ) or remaining in a high risk of TC (difference in $\log$ WMHV 0.14 , p value 0.04 ) was associated with a greater WMHV, using those remaining at low risk as the reference group. We found no associations of change in LDL-C with WMHV.

Lipid Profile and Subclinical Cerebrovascular Disease

\section{Association between Plasma Lipid Profile Components and $S B I$}

We found no association between any of the plasma lipid profile components at baseline or with change over time and SBI (table 5), and there were no interactions for treatment with cholesterol-lowering medications, apoE isoforms, or baseline sociodemographic factors. 


\section{Discussion}

In our analyses we found that plasma lipids at initial enrollment were not associated with total WMHV or SBI. However, the associations between TC and total WMHV differed by apoE isoform status, with a trend towards an association of TC with WMHV only among those with an apoE4 genotype. Unlike other studies [21] we did not find that higher levels of HDL-C were associated with larger WMHV. Furthermore we found no association of any lipid components with subclinical infarction. We did, however, find that increases in plasma lipids over an average of 6 years between baseline enrollment and the time of MRI were associated with greater WMHV, notably with a transition from low-risk categories to a high-risk category for HDL-C and TC. We further found that treatment with cholesterol-lowering medications did not modify the associations with the plasma lipid profile components.

There are few published studies examining the association between plasma lipid profile components and subclinical cerebrovascular disease. Two recent studies showed an association between dyslipidemia and lower WMHV, one study being a community cohort referred for clinical MRI [22] and another an analysis of acute ischemic stroke patients [10]. The largest study to date has been the Cardiovascular Health Study, which demonstrated increased WMHV over time among participants with high HDL-C and low LDL-C [21]. These studies, however, did not consider more than one lipid measure over time, or an interaction with genetic risk factors. The genetic determinants of WMHV are an area of controversy, with a recent meta-analysis showing no clear association with apoE isoforms [23]. Previous studies have examined the role of the interaction between the plasma lipid profile components and apoE isoforms (especially apoE4) in informing the risk of Alzheimer's disease, as well as coronary artery disease [11], but subclinical cerebrovascular disease is not well reported.

There are several possible explanations for our findings. The lack of association with SBI may be similar to the findings seen in other studies for ischemic stroke [24], particularly among the nonatherosclerotic subtypes [7]. The pathology of most SBI is similar to lacunar infarction due to lipohyalinosis in small cerebral penetrating arteries that may not be related to dyslipidemia [25]. On the other hand we may be underpowered to detect more subtle effects of plasma lipid profile components on SBI given the binary nature of this variable and the low prevalence of SBI given the young age of our cohort at the time of MRI. The pathology of WMH remains an area of active investigation, and though ischemic etiologies are frequently invoked, other pathological features have also been postulated including neurodegeneration, demyelination, gliosis, edema, and inflammation [26]. The lack of an association in our study between LDL-C, the principal target of treatment with statins for stroke prevention, and WMHV supports these nonischemic etiologies. In nonischemic etiologies, dyslipidemia may play a limited or seemingly paradoxical role suggesting a degenerative process. The association of plasma lipid profile components with WMH parallels that of the findings with intracerebral hemorrhage [27] and symptomatic intracranial hemorrhage after thrombolysis [28, 29], further raising the possibility of an association with nonischemic etiologies such as cerebral amyloid angiopathy or disruption in vascular endothelium [30]. Similarly the role of dyslipidemia with ischemic stroke, which is more likely to share pathological features with SBI, remains controversial [3]. ApoE4 isoforms are associated with increased levels of TC and LDL-C as well as a greater affinity for binding to the LDL receptor, which have both been implicated in the increased association with atherosclerotic disease. In the central nervous system the apoE4 isoform has also been implicated in reduced glial cell repair in response to amyloid $\beta$ and reactive oxygen species damage. This effect may be in part due to reduced transport of cholesterol moieties across the blood-brain barrier and into the intracellular domains [11], in keeping with the important role cholesterol plays in synaptogenesis and neural repair [31]. Our results showing an independent effect of a worsening plasma lipid profile, however, also suggest that atherosclerosis may play a role in the formation of WMH and highlights the importance of considering temporal trends in risk factors.

Our findings could also be due to nonbiological mechanisms stemming from study design. The MRI cohort was enrolled several years after the initial lipid profile was obtained, and survival bias may therefore have led to enrollment of only those who had a genetic predisposition to a reduced effect from dyslipidemia on stroke or death. This is an unlikely explanation for our findings since in previous analyses we have not shown significant differences in baseline modifiable stroke risk factors, including lipid panel, between those enrolled in the MRI cohort and the rest of the cohort. We did not collect information on the size of the SBI, which in a recent study was found to lead to an association of plasma lipids with SBI larger than $8 \mathrm{~mm}$ (where there may be microatheromatous disease), rather than in smaller SBI where lipohyalinosis may be 
more important [25]. The results for WMHV and SBI are nonetheless in keeping with other cohort studies failing to show an association between ischemic stroke and dyslipidemia $[9,32,33]$. Low HDL-C and high TG are components of the metabolic syndrome, which is associated with risk of ischemic stroke $[34,35]$ as well as subclinical cerebrovascular disease [36]. It is thus possible that lipid profile parameters in themselves are not risk factors for subclinical cerebrovascular disease, but instead act in combination with other components of the metabolic syndrome.

Our study has several strengths, including a representative sample of three different race/ethnic groups, repeated measurement of plasma lipid profile components, capture of treatment with cholesterol-lowering medications, and consideration of the interaction with apoE isoforms. There are several limitations of the findings in our study. Participants had only one MRI and we therefore lack information on the progression of WMH or incident SBI, and we are unable to determine cause and effect. In addition, it is possible that the lipid profile may have a different impact on the progression of MRI findings compared to these cross-sectional associations. The number of SBI may have been too small to examine more subtle associations with dyslipidemia. We may have been underpowered to detect an interaction by sex, age, race-ethnicity, or medication use, and thus we are not able to comment on differences by these important baseline factors. Lastly, we examined for interactions between several lipid profile components and apoE isoforms and it is possible that our findings of differential effects may have been due to chance. Nonetheless, our findings are in keeping with other studies that have shown either a paradoxical [10,21,22] or no association [37] between plasma lipid profile components and subclinical cerebrovascular disease.

In conclusion, our study showed that the association of lipid profile components with WMH was modified by apoE genotype as well as changes of lipid profile components over time. As the population continues to age the clinical manifestations of subclinical cerebrovascular disease will take on a greater role, and so will the importance of identifying risk factors and potential treatment targets. At this time the data has been inconclusive on the utility of statins in preventing an increase in WMHV $[38,39]$ or SBI [40], though the efficacy in preventing clinical stroke is clear [6]. Further research is needed on identifying risk factors for subclinical cerebrovascular disease and how these modifiable diseases are influenced by an individual's genetic profile.

\section{Acknowledgments}

Funding for this project was provided by NIH/NINDS R37 NS 29993 and the Evelyn F. McKnight Brain Institute (U. Miami). J.Z.W. was funded by NINDS K23 NS 073104. C.D. was funded by NIH/NIA P30 AG 10129.

\section{Disclosure Statement}

H.G., Y.P.M., M.Y., Y.K.C., R.L.S., M.S.V.E., and C.B.W. report no financial conflicts of interest.

\section{References}

$\checkmark 1$ Debette S, Beiser A, DeCarli C, Au R, Himali JJ, Kelly-Hayes M, Romero JR, Kase CS, Wolf PA, Seshadri S: Association of MRI markers of vascular brain injury with incident stroke, mild cognitive impairment, dementia, and mortality: the Framingham Offspring Study. Stroke 2010;41:600-606.

$\checkmark 2$ LADIS Study Group: 2001-2011: a decade of the LADIS (Leukoaraiosis And DISability) Study: what have we learned about white matter changes and small-vessel disease? Cerebrovasc Dis 2011;32:577-588.

3 Cholesterol, diastolic blood pressure, and stroke: 13,000 strokes in 450,000 people in 45 prospective cohorts. Prospective studies collaboration. Lancet 1995;346:1647-1653.

$\checkmark 4$ Wilson PW, Anderson KM, Harris T, Kannel WB, Castelli WP: Determinants of change in total cholesterol and HDL-C with age: the Framingham Study. J Gerontol 1994;49:M252-M257.
5 Byington RP, Davis BR, Plehn JF, White HD, Baker J, Cobbe SM, Shepherd J: Reduction of stroke events with pravastatin: the Prospective Pravastatin Pooling (PPP) Project. Circulation 2001;103:387-392.

-6 Amarenco P, Bogousslavsky J, Callahan A 3rd, Goldstein LB, Hennerici M, Rudolph AE, Sillesen H, Simunovic L, Szarek M, Welch $\mathrm{KM}$, et al: High-dose atorvastatin after stroke or transient ischemic attack. N Engl J Med 2006;355:549-559.

-7 Tirschwell DL, Smith NL, Heckbert SR, Lemaitre RN, Longstreth WT Jr, Psaty BM: Association of cholesterol with stroke risk varies in stroke subtypes and patient subgroups. Neurology 2004;63:1868-1875.

8 Brown WR, Moody DM, Challa VR, Thore CR, Anstrom JA: Venous collagenosis and arteriolar tortuosity in leukoaraiosis. J Neurol Sci 2002;203-204:159-163.
9 Willey JZ, Moon YP, Paik MC, Yoshita M, Decarli C, Sacco RL, Elkind MS, Wright CB: Lower prevalence of silent brain infarcts in the physically active: the Northern Manhat$\tan$ Study. Neurology 2011;76:2112-2118.

10 Jimenez-Conde J, Biffi A, Rahman R, Kanakis A, Butler C, Sonni S, Massasa E, Cloonan L, Gilson A, Capozzo K, et al: Hyperlipidemia and reduced white matter hyperintensity volume in patients with ischemic stroke. Stroke 2010;41:437-442.

11 Mahley RW, Rall SC Jr: Apolipoprotein E: far more than a lipid transport protein. Annu Rev Genomics Hum Genet 2000;1: 507-537.

12 Prabhakaran S, Wright CB, Yoshita M, Delapaz R, Brown T, DeCarli C, Sacco RL: Prevalence and determinants of subclinical brain infarction: the Northern Manhattan Study. Neurology 2008;70:425-430.
Lipid Profile and Subclinical

Cerebrovascular Disease
Cerebrovasc Dis 2014;37:423-430 DOI: $10.1159 / 000362920$ 
$>13$ Sacco RL, Anand K, Lee HS, Boden-Albala B, Stabler S, Allen R, Paik MC: Homocysteine and the risk of ischemic stroke in a triethnic cohort: the NOrthern MAnhattan Study. Stroke 2004;35:2263-2269.

$\checkmark 14$ Paultre F, Tuck CH, Boden-Albala B, Kargman DE, Todd E, Jones J, Paik MC, Sacco RL, Berglund L: Relation of Apo(a) size to carotid atherosclerosis in an elderly multiethnic population. Arterioscler Thromb Vasc Biol 2002; 22:141-146.

15 Friedewald WT, Levy RI, Fredrickson DS: Estimation of the concentration of low-density lipoprotein cholesterol in plasma, without use of the preparative ultracentrifuge. Clin Chem 1972;18:499-502.

$>16$ Nordestgaard BG, Benn M: Fasting and nonfasting LDL cholesterol: to measure or calculate? Clin Chem 2009;55:845-847.

$>17$ Hixson JE, Vernier DT: Restriction isotyping of human apolipoprotein E by gene amplification and cleavage with HhaI. J Lipid Res 1990; 31:545-548.

-18 DeCarli C, Miller BL, Swan GE, Reed T, Wolf PA, Garner J, Jack L, Carmelli D: Predictors of brain morphology for the men of the NHLBI twin study. Stroke 1999;30:529-536.

19 DeCarli C, Murphy DG, Tranh M, Grady CL, Haxby JV, Gillette JA, Salerno JA, GonzalesAviles A, Horwitz B, Rapoport SI, et al: The effect of white matter hyperintensity volume on brain structure, cognitive performance, and cerebral metabolism of glucose in 51 healthy adults. Neurology 1995;45:20772084.

20 Expert Panel on Detection, Evaluation, and Treatment of High Blood Cholesterol in Adults: Executive Summary of The Third Report of The National Cholesterol Education Program (NCEP) Expert Panel on Detection, Evaluation, And Treatment of High Blood Cholesterol In Adults (Adult Treatment Panel III). JAMA 2001;285:2486-2497.

-21 Longstreth WT Jr, Arnold AM, Beauchamp NJ Jr, Manolio TA, Lefkowitz D, Jungreis C, Hirsch CH, O'Leary DH, Furberg CD: Incidence, manifestations, and predictors of worsening white matter on serial cranial magnetic resonance imaging in the elderly: the Cardiovascular Health Study. Stroke 2005;36: 56-61.
22 Ichikawa H, Mukai M, Ohno H, Shimizu Y, Itaya K, Kawamura M: Deep white matter hyperintensities, decreased serum low-density lipoprotein, and dilative large arteriopathy. J Stroke Cerebrovasc Dis 2012;21:225-230.

23 Paternoster L, Chen W, Sudlow CL: Genetic determinants of white matter hyperintensities on brain scans: a systematic assessment of 19 candidate gene polymorphisms in 46 studies in 19,000 subjects. Stroke 2009;40:2020-2026.

24 Willey JZ, Xu Q, Boden-Albala B, Paik MC, Moon YP, Sacco RL, Elkind MS: Lipid profile components and risk of ischemic stroke: the Northern Manhattan Study (NOMAS). Arch Neurol 2009;66:1400-1406.

25 Bezerra DC, Sharrett AR, Matsushita K, Gottesman RF, Shibata D, Mosley TH Jr, Coresh J, Szklo M, Carvalho MS, Selvin E: Risk factors for lacune subtypes in the Atherosclerosis Risk in Communities (ARIC) Study. Neurol ogy 2012;78:102-108.

26 Gouw AA, Seewann A, Vrenken H, van der Flier WM, Rozemuller JM, Barkhof F, Scheltens P, Geurts JJ: Heterogeneity of white matter hyperintensities in Alzheimer's disease: post-mortem quantitative MRI and neuropathology. Brain 2008;131:3286-3298.

27 Martini SR, Flaherty ML, Brown WM, Haverbusch M, Comeau ME, Sauerbeck LR, Kissela BM, Deka R, Kleindorfer DO, Moomaw CJ, et al: Risk factors for intracerebral hemorrhage differ according to hemorrhage location. Neurology 2012;79:2275-2282.

28 Messe SR, Pervez MA, Smith EE, Siddique KA, Hellkamp AS, Saver JL, Bhatt DL, Fonarow GC, Peterson ED, Schwamm LH: Lipid profile, lipid-lowering medications, and intracerebral hemorrhage after tPA in Get With the Guidelines-Stroke. Stroke 2013;44:13541359.

29 D’Amelio M, Terruso V, Famoso G, Ragonese P, Aridon P, Savettieri G: Cholesterol levels and risk of hemorrhagic transformation after acute ischemic stroke. Cerebrovasc Dis 2011; 32:234-238.

30 Chen YW, Gurol ME, Rosand J, Viswanathan A, Rakich SM, Groover TR, Greenberg SM, Smith EE: Progression of white matter lesions and hemorrhages in cerebral amyloid angiopathy. Neurology 2006;67:83-87.

-31 Mauch DH, Nagler K, Schumacher S, Goritz C, Muller EC, Otto A, Pfrieger FW: CNS synaptogenesis promoted by glia-derived cholesterol. Science 2001;294:1354-1357.
32 Shahar E, Chambless LE, Rosamond WD, Boland LL, Ballantyne CM, McGovern PG, Sharrett AR: Plasma lipid profile and incident ischemic stroke: the Atherosclerosis Risk in Communities (ARIC) study. Stroke 2003;34: 623-631.

33 Psaty BM, Anderson M, Kronmal RA, Tracy RP, Orchard T, Fried LP, Lumley T, Robbins J, Burke G, Newman AB, et al: The association between lipid levels and the risks of incident myocardial infarction, stroke, and total mortality: The Cardiovascular Health Study. J Am Geriatr Soc 2004;52:1639-1647.

34 McNeill AM, Rosamond WD, Girman CJ, Golden SH, Schmidt MI, East HE, Ballantyne CM, Heiss G: The metabolic syndrome and 11-year risk of incident cardiovascular disease in the atherosclerosis risk in communities study. Diabetes Care 2005;28:385-390.

$>35$ Boden-Albala B, Sacco RL, Lee HS, GrahameClarke C, Rundek T, Elkind MV, Wright C, Giardina EG, DiTullio MR, Homma S, et al: Metabolic syndrome and ischemic stroke risk: Northern Manhattan Study. Stroke 2008;39: 30-35.

36 Yates KF, Sweat V, Yau PL, Turchiano MM, Convit A: Impact of metabolic syndrome on cognition and brain: a selected review of the literature. Arterioscler Thromb Vasc Biol 2012;32:2060-2067.

37 Rost NS, Rahman R, Sonni S, Kanakis A, Butler C, Massasa E, Cloonan L, Gilson A, Delgado $\mathrm{P}$, Chang $\mathrm{Y}$, et al: Determinants of white matter hyperintensity volume in patients with acute ischemic stroke. J Stroke Cerebrovasc Dis 2010;19:230-235.

38 Mok VC, Lam WW, Fan YH, Wong A, Ng PW, Tsoi TH, Yeung V, Wong KS: Effects of statins on the progression of cerebral white matter lesion: post hoc analysis of the ROCAS (Regression of Cerebral Artery Stenosis) study. J Neurol 2009;256:750-757.

39 ten Dam VH, van den Heuvel DM, van Buchem MA, Westendorp RG, Bollen EL, Ford I, de Craen AJ, Blauw GJ: Effect of pravastatin on cerebral infarcts and white matter lesions. Neurology 2005;64:1807-1809.

$40 \mathrm{Fu} \mathrm{JH}$, Mok V, Lam W, Wong A, Chu W, Xiong Y, Ng PW, Tsoi TH, Yeung V, Wong KS: Effects of statins on progression of subclinical brain infarct. Cerebrovasc Dis 2010;30:51-56. 